\title{
Audit in psychiatry
}

\author{
Gillian Garden, Registrar in Psychiatry; Femi Oyebode, Consultant Psychiatrist \\ (correspondence); and STUART Cumella, Director of Planning, John Conolly \\ Hospital, Birmingham B45 9BD
}

Medical audit has been defined as the systematic, critical analysis of the quality of medical care, including the procedures used for diagnosis and treatment, the use of resources and the resulting outcome and quality of life for the patient (DOH, 1989). The White Paper Working for Patients states that the Government proposes that every consultant should participate in a form of medical audit agreed between management and the profession locally. It also states that management should be able to initiate an independent professional audit.

There is a paucity of published work on audit within psychiatry in the UK. This article sets out to review the world literature on audit in psychiatry, drawing attention to the benefits, problems and limitations of audit. Finally, we aim to propose strategies for the development of audit in psychiatry in this country.

\section{Methods of medical audit}

In 1972, the USA Congress passed legislation requiring the establishment of local professional standards review organisations (PSROs) to oversee utilisation reviews and medical care evaluation studies done by hospitals.

The PSROs consisted of voluntary associations of physicians in a given area. They were charged with determining the medical necessity for hospitalisation, establishing the initial limit for hospital stay and approving or disapproving extension of hospital status. In addition, medical care evaluation studies were required and auditing was set up to examine the treatment given to selected patients over time. All plans had to be approved by the Secretary of Health Education and Welfare.

The PSROs have had mixed results; reports have indicated that a drop in admission rates and in length of stay were attributable to the activities of PSROs. Furthermore, other studies showed that peer review was responsible for large reductions in medically unnecessary injections and inappropriate polypharmacy and in a reduction in costs by curbing improper utilisation and abuses of practice. Although one study demonstrated a saving of four dollars for each one dollar spent on the PSRO programme, the evidence that they curtailed costs is scanty; indeed health costs continued to escalate. By 1978 the PSRO budget was $\$ 120$ million and was continuing to grow. A further criticism levelled at the PSROs was that they assessed patient care by examining conformity to previously established guidelines. A method which assumed that close conformity maximised favourable outcome may have been unjustified since process and outcome criteria correlate poorly (Brook, 1973).

At approximately the same time, another American organisation, the Joint Commission on Accreditation of Hospitals (JCAH), developed an audit system and by 1977 psychiatric facilities were required to conduct a specified number of patient care evaluations. The JCAH imposed rigid audit quotas without establishing adequate audit methodology, and it also focused on diagnosis related groups (DRGs) which resulted in a superficial overview rather than identification of problems in patient care. DRGs are a system of per case prospective payment used for the majority of patients covered by Medicare. Once again, the organisation was costly without obvious benefit. More recently it has made greater effort to ensure integration of quality assurance programmes so that problem areas are identified, studied and resolved. Furthermore, greater flexibility has been allowed on how facilities identify, assess and resolve these problems so that individual hospitals can select methods pertinent to their situation.

Since 1986, all health care institutions in Canada have been required to have an active quality of care programme in order to be eligible for the maximum accreditation award for three years. The programme includes all components of hospitals; health care, support services and the administration.

The Netherlands have had quality assurance (QA) programmes for several years. In 1985, it became a legal requirement for health care professionals to participate in the development of QA programmes, although the national organisation for quality assurance in hospitals (CBO) was set up in 1979. The National Hospital Association (NZR) instituted a hospital QA package called the Hospital Audit Project which has been running for three years. Hospital inspections consist of a visiting team of nine or ten people (three from NZR, the rest being 
clinicians from other hospitals) who spend four days analysing the service provided and produce a series of recommendations. No sanctions exist to ensure compliance but in extreme cases the institution concerned can be called to account for its inaction by the council of NZR. The CBO invests much time in discussions with professional associations on the theory and practice of QA which leads to the development of training packages and 'on site' education, QA priority setting and review techniques. The CBO also trains the officers of the state inspectorate for health.

Coupe (1988) visited the Netherlands to obtain first hand experience of these organisations. He found some impressive examples but stressed that these practices were not nationwide. He also felt that these programmes had a crucial dependence on staff with a strong commitment to the projects and he noted that the enthusiasm for QA only became apparent after the legislation of 1985 . There were also problems of liaison between the inspectorate, clinicians and other mental health workers, as well as between 'biological' and 'psychosocial' psychiatrists respectively. Furthermore, the $\mathrm{CBO}$ has been criticised for being exclusively medical and for having shown little interest in psychiatry. To some extent this was a conscious decision on account of the difficulty of measuring quality in psychiatry and the difference of opinion and practice between different psychiatrists.

QA in this country has yet to be fully developed. A Government body, the Health Advisory Service (HAS), was established to avoid a repetition of scandals such as that which occurred at Ely Hospital. HAS teams visit health and related services for mentally ill and elderly people. Visiting teams comprise experienced professionals who offer an independent view of the quality of services provided. Visits culminate in reports to the authorities concerned and to government ministers and since 1985 these reports have been published. However, the HAS has no power to enforce its recommendations and relies on the effect of its reputation and the credibility of its staff. It also highlights areas of concern and publishes reports on focal issues. Other examples of formal institutional audit include the Mental Health Act Commission (MHAC), the MHAC Second Opinion system, the Mental Health Review Tribunals and the Approval Exercise of the Royal College of Psychiatrists.

A team from Southampton have published an interesting report on their experiences of psychiatric audit which was initiated in response to a 'prolonged crisis' involving a large number of suicides in a unit with stretched resources. Initially ad hoc meetings were held whenever there was a successful or near successful suicide, but later regular audit meetings were held to examine aspects of routine clinical care. Randomly selected in-patient and out-patient files were given to an independent consultant to review. Since this method centred too specifically on the adequacy of notes, the meetings progressed to examination of specific areas of the service at each meeting. Meetings on management of detained patients, prescription cards, assaults, and variations in length of stay of patients with similar diagnoses on different wards were held. The criticisms that emerged could be categorised into those predominantly concerned with note keeping and those concerned.with patient care. They believed that the former promoted better record keeping while the latter helped in overall standard of clinical practice. The authors stressed the importance of emphasising the essentials of good care appropriate to the circumstances. They also ensured complete confidentiality of proceedings by deleting any mention of names of doctors or patients (Edwards et al, 1987).

\section{Advantages, criticisms and limitations}

QA has been embraced by other medical specialities in this country without government pressure, which suggests that audit may offer advantages over and above those of resource management. McIntyre \& Popper (1983) reviewed these advantages and argued that current knowledge far exceeds what any one person can know and therefore mistakes and erroneous assumptions are inevitable. They went on to say that although knowledge may grow by accumulation, far more often it grows by the recognition of error. If experiences are pooled as in medical audit, doctors may learn from the errors of others as much as from their own. Thus audit can play an important role in enhancing learning. Better informed doctors, it is argued, should provide better patient care; with the reduction in idiosyncratic practice, patients might receive a better service irrespective of where or by whom they are treated. This assumes that the level of funding is appropriate to the area's needs.

Audit is not without its critics. Horrobin (1982) has questioned the appropriateness of peer review for assessing the value of scientific work. It is essential that we note his criticisms since excessive standardisation in a speciality such as psychiatry, where so much remains to be discovered, might impede rather than advance our knowledge. However, there is no reason why diversification and research might not occur, provided that basic, agreed standards of care were maintained.

Confidentiality and the erosion of the doctorpatient relationship have been repeated issues of concern; some doctors believe that audit would threaten this relationship and believe that the doctor's authority would dwindle should patients hear of mistakes or that their cases might be discussed by others. While these concerns might be justified, the possibility that 
patients would welcome attempts to improve clinical performance should not be ignored.

There has been much discussion in the American, Canadian and Australian literature about the medico-legal implications of peer review. It is conceivable that untoward occurrences reviewed by quality assurance committees might, at a later stage, be the subject of medical negligence actions. If the plaintiff's solicitors were aware of the existence of such committees and reports, it is likely that there would be an attempt to gain access to the relevant records in order to prove negligence.

Another medico-legal problem which has arisen in the USA may also deter doctors from participating in QA. This problem relates to the result of an antitrust case, Patrick v. Burget $e t$ al, in which a federal jury rendered a judgement totalling more than $\$ 2$ million against 11 physicians. These doctors allegedly used the peer review process to remove a surgeon in the community as a competitor. Several of them had served on a peer review committee at the local hospital and also on a committee of the Oregon Board of Medical Examiners which investigated the conduct of surgeon Timothy Patrick, after a number of complaints. Before the hospital committee could take any action on Patrick's privileges, he resigned and sued the hospital for conspiracy to restrain practice (Riffer, 1986).

In the USA, the Health Care Quality Improvement Act of 1986 has granted limited immunity to medical practitioners participating in peer review, since part of the act is based on a finding by Congress that there "is an overriding national need to provide incentive and protection for physicians engaging in effective professional peer review" (George \& Rouse, 1987). In Australia and Britain, there is little protection for doctors whose statements recorded in peer review committees might be used against them in subsequent medical negligence actions. Thus, the importance to the peer review process of obtaining such a statutory protection cannot be overstated and no doubt the reluctance of some practitioners to participate will continue until protection is obtained. Alternatively, doctors may protect themselves by omitting names, or more drastically by destroying records of peer review, as has happened in Canada. The difficulty with the former in psychiatry is that names are not required to identify a subject from a history, unlike other medical specialities.

Psychiatry poses particular difficulties when considering quality assurance. The debate over how to establish priorities exists in all fields, but it is perhaps more difficult in psychiatry where there is lack of objective criteria and an absence of a universally accepted standard for the classification of psychiatric disorders. To some extent, the latter is being resolved with DSM-III and ICD-9/10 criteria, but these are not universally accepted or used. There have been extensive discussions about what criteria should be used in the mental health field. Donabedian (1980) advocates the implicit criteria, that is criteria which are based on the education and experience of the reviewers since they represent more clearly local and individual needs and accommodate professional considerations that are not represented in any particular set of predetermined criteria. He accepts that the latter are more predictable and consistent, but feels that they may be viewed as instruments of control and can impose an oppressive and misguided uniformity.

Irrespective of the type of criteria employed, problem areas which are most in need of study and resolution must be identified so that priorities are set. Psychiatrists must also be aware that their priorities may differ from those defined by other groups, e.g. nursing staff, social workers, managers and patients. These groups may also have differing perspectives on what constitutes a favourable outcome.

Brook and his associates (1982) have reviewed the difficulty in setting management and outcome criteria in mental health. They emphasise that for criteria to be valid, one must have good reason to believe that changes in management would bring about improvements in the health status of patients. They caution against attributing differences or deficiencies in outcome to the health care system, when they could be attributed elsewhere (a great deal of variation in outcome arises from factors outside quality of services).

\section{Proposals and conclusions}

The institution of audit within psychiatry could occur in a variety of ways. Peer review organisations in the mode of the USA experience could be set up or the HAS could be expanded to fulfil this role. The advantage of this direction would be the development of national standards and norms. However, excessive standardisation could be counterproductive, and in addition a national organisation is unlikely to be able to visit on a frequent enough basis. External assessors are likely to be perceived as threatening and issues of confidentiality and of the possibility of medico-legal implications would arise since formal records of proceedings would probably be made. Finally, the cost of this choice could be prohibitive; the failure of PSROs to make an impact on the overall cost or standard of health care in the USA suggest this.

In our view, the most effective form of audit would be peer review developed on a voluntary basis by groups of clinicians in each hospital or district. These clinicians would determine the appropriate standards of care which reflected the local needs. The method of audit should be objective, repeatable, and 
inexpensive. Provision of administrative staff by management would be of benefit. Frequent meetings, occurring at least monthly, would maximise the value of audit and reduce its perceived threat. Furthermore, we recommend that no formal records be kept until the medico-legal implications are clarified.

Case note review is probably the best initial step, and the case notes should be selected at random by an independent chairman; each case should be presented by the doctor best acquainted with the case. When the practice of audit has become established, other topics

\section{References}

Brook, R. H. (1973) Quality of Care Assessment: A Comparison of Five Methods of Peer Review. Washington: Government Printing Office.

-, KAMBERG, C. \& LOHR, K. (1982) Quality assessment in mental health. Professional Psychology, 13, 34-39.

COUPE, M. (1988) Quality assurance and psychiatry: Reflections on the Dutch experience. Health Services Management, June, 24-27.

DePartment of Health (1989) Working for Patients: Medical Audit. London: HMSO.

DONABEDian, A. (1980) The definition of quality and approaches in its assessment. Explorations in Quality Assessment and Monitoring, Vol. I. Ann Harbor, Michigan: Health Administration Press.

Edwards, G., NunN, C. M. H. \& CretTs, B. S. (1987) such as out-patient care, management of suicide, parasuicide, and detained patients could come under focus. The experience of the Southampton team suggests that while standards of note-keeping is important, it is vital that it does not overshadow consideration of the overall quality of care (Edwards et al, 1987).

In conclusion, the importance of auditin psychiatry cannot be overstated. Its institution in an appropriate and sympathetic way is likely to guarantee its success, and thereby to affirm its place within our everyday practice.

Three years of medical audit in a psychiatric unit. Bulletin of the Royal College of Psychiatrists, 11, 154-155.

GeORGE, J. E. \& Rouse, A. R. (1987) The Health Care Quality Improvement Act of 1986. New Jersey Medicine, $84,401-403$.

HoRrobin, D. F. (1982) Peer review: A philosophically faulty concept which is proving disastrous for science. Behavioural and Brain Sciences, 5, 217-218.

MCINTYRE, N. \& POPPER, K. (1983) The critical attitude in medicine: the need for a new ethics. British Medical Journal, 287, 1919-1923.

RIFFER, J. (1986) Antitrust law and peer review remain at odds. Hospitals, 60, 58.

$A$ full list of references is available on request from the senior author.

\section{Medical audit in psychiatry}

\section{or Fear and loathing on the White Paper trail}

\section{Christopher Holman, Senior Registrar, Department of Psychiatry, St George's Hospital, Tooting, London SW17}

The Government White Paper, Working for Patients (1989), although presented as a discussion document, should be seen as a position paper. It is clear that the government intends to implement the major proposals, and will be able through its control of general management, enhanced by a stream-lined management structure (Working for Patients para 2.32.11), to put pressure on health authorities to take action accordingly.
Psychiatrists should not allow the placing of mental health services in the 'core services' (Working for Patients para 4.15-4.18) to lead them into complacency. Reading the White Paper in conjunction with Community Care: Agenda For Action (1988) makes clear the likely direction of future policy. Once the general acute services are established in their semi-autonomous NHS Trusts, they will be encouraged to tender for the acute aspects of mental health 